\title{
Changes in stereotyped behaviour following acute or repeated methylenedioxy-methamphetamine (MDMA) treatment Susanna Szelényi ${ }^{1}$, Ágnes Bajnogel-Orosz'1, Julia Timár*1, Susanna Gyarmati ${ }^{1}$, Melinda Sobor ${ }^{1,2}$ and Susanna Fürst ${ }^{1,3}$
}

Address: ${ }^{1}$ Department of Pharmacology and Pharmacotherapy, Semmelweis University, Budapest, Hungary, ${ }^{2}$ National Institute of Pharmacy, Budapest, Hungary and ${ }^{3}$ HAS-SE Neuropsychopharmacology Research Group, Budapest, Hungary

Email: Julia Timár* - timjul@pharma.sote.hu

* Corresponding author

from 13th Scientific Symposium of the Austrian Pharmacological Society (APHAR). Joint Meeting with the Austrian Society of Toxicology (ASTOX) and the Hungarian Society for Experimental and Clinical Pharmacology (MFT)

Vienna, Austria. 22-24 November 2007

Published: 14 November 2007

BMC Pharmacology 2007, 7(Suppl 2):A46 doi:10.1 I86/I47I-2210-7-S2-A46

This abstract is available from: http://www.biomedcentral.com/I47I-22/0/7/S2/A46

(c) 2007 Szelényi et al; licensee BioMed Central Ltd.

\section{Objective}

In our previous experiments a decrease of the MDMAinduced 5-HT syndrome (HTS) was observed following repeated administration of the dextrorotatory (d) enantiomer of MDMA. The aim of the present study was to examine how the dopamine agonist-induced stereotyped behaviour (SB) alters following single or repeated dMDMA treatment.

\section{Methods}

Wistar male rats were treated with single or repeated (4 times with 2 hours intervals) doses $(10 \mathrm{mg} / \mathrm{kg})$ of $\mathrm{d}$ MDMA. Three, 7 and 14 days later the intensity of dMDMA-induced HTS and SB was examined. The SBinducing effect of d-amphetamine (AM) and apomorphine (APO) was also checked.

\section{Results}

(1) Following repeated administration of d-MDMA the intensity of MDMA-induced HTS decreased while that of SB increased. (2) Single dose pretreatment with d-MDMA did not influence the d-MDMA-induced HTS but enhanced the SB. (3) The d-AM-induced SB also increased while the APO-induced SB did not change.

\section{Conclusion}

A single dose of d-MDMA, which, in contrast to the repeated treatment, did not alter the 5-HT-related behaviour, may already result in development of DA sensitization.

\section{Acknowledgements}

This work was supported by Hungarian grants OTKA K-60999 and ETT$44 I / 2006$ 